\title{
SURGERY IN SEVERE ESSENTIAL HYPERTENSION
}

\author{
By Frank D'Abreu, Ch.M., F.R.C.S. \\ Assistant Surgēon, Westminster Hospital
}

Essential hypertension, according to Poppen and Lemmon (1947) ${ }^{1}$ is four times as deadly as cancer, and Lee MacGregor ${ }^{2}$, quoting these figures and other gloomy statistics of this disease, describes it as Public Enemy No. I. A report from the Metropolitan Life Assurance Company of New York ten years previously, less graphic but more chilling, states that half a million deaths occur annually in the United States from hypertension, and that after the age of 45 the death rate for this disease is four times that of cancer and 20 times that of tuberculosis or diabetes.

As the true cause of essential hypertension is still unknown, treatment can only be directed towards the effects of the disease. Surgically, attempts have been made to lower the blood pressure by removing portions of the sympathetic chain. This has been done by operations which have tended, year by year, to increase in their extent.

\section{Sympathectomy}

I. Criles operation. In this, through a small incision in the loin, the coeliac ganglion is removed by deep and blind dissection. This technique is a most difficult and individualistic form of removing only a part of what has been excised by later methods.

2. Adson's sub-diaphragmatic approach. In this operation the main lumbar sympathetic chain is exposed and removed from the crus of the diaphragm to below the second lumbar ganglion. In addition, portions of the greater, lesser and least splanchnic nerves and the coeliac ganglion are excised. This has been combined on occasions with partial adrenalectomy.

Adson has shown good results from this operation but his critics complain that the sympathectomy possible by this approach is not extensive enough. A more practical objection is that the identification of all the nerves to be removed can not be facilitated by tracing them down from above the diaphragm, as is done in Smithwick's lumbodorsal sympathectomy.

Removal of part of the adrenal has yielded disappointing results so far as any permanent effect in lowering the blood pressure is concerned and is said to increase greatly the dangers of the operation from post-operative hypotensive crises.

3. Peet's method. Here the sympathetic chain and the splanchnic nerves are exposed transthoracically and traced downwards.

4. Smithwick's method. This combines the thoracic and sub-diaphragmatic approaches and is described in detail below.

5. In an effort to excise more and more of the sympathetic nervous system, some surgeons now open the chest and attack the sympathetic chain trans-pleurally. The chain can be removed up to the level of the second ganglion by this means and the para-aortic sympathetic nerve excised as well as the nerves which are removed by Smithwick's method. Although it is claimed that the coeliac ganglion and the first lumbar ganglion can be removed by this approach, no exploration of the adrenal gland and the kidney can be carried out and the second lumbar ganglion cannot be reached unless the diaphragm be opened and the operation thus made more formidable. This has the advantage of being an easier approach, but experience and careful assessment of mortality figures and results, under controlled conditions, can alone show if this method is better than Smithwick's.

6. Multiple sympathectomies through separate chest and loin incisions have been advocated, but the limit, it seems, has already been reached by Grimson ${ }^{3}$, who performs sometimes a complete bilateral removal of the whole sympathetic nervous system.

In assessing these operations it must be remembered that sympathectomy at its best is only removing a link in the chain of this disease. It will not be until the more radical sympathectomies can show, in cases comparable in number with those of Peet ${ }^{4}$ and Smithwick ${ }^{5}$, a longer survival period and an equally low mortality rate, that they can be deemed the better form of surgical treatment.

There has been much discussion of recent years concerning the selection of cases of essential hypertension for surgery. By means of sedation tests and by methods of epidural block anaesthesia mimicking the effects of sympathectomy, it has been hoped to discover which cases are suitable for 
removal of the pressor influence of the sympathetic nervous system. Doubt has been thrown lately by some authorities, on the value of such tests and in the group of severe cases discussed in this paper the view has been taken that as symptomatic relief may be attained even without permanent lowering of the blood pressure, every case should be given the chance of operation. The cases chosen are those with the worst prognosis and include :

(I) Definitely 'malignant' hypertensives.

(2) Those with a fixed diastolic pressure around $150^{\circ}$.

(3) Those with a clear history of encephalopathic incidents.

[Smithwick advises against operation in a male patient with a resting diastolic pressure of 140 or more, who has a history of an encephalopathic accident, or has evidence of cardiac or renal impairment.]

The criterion of malignancy is not universally clear and definite. At a meeting held in Cleveland in 1942 de Takats ${ }^{6}$ and Smithwick spoke at cross purposes until de Takats revealed that what he had been describing as malignant hypertension was a case of papilloedema combined with renal and cardiac damage. Many others consider 'papilloedema' as the sole criterion. Some ophthalmic surgeons, however, say that the term papilloedema should be reserved for spaceoccupying lesions within the skull and consider that papilloedema in malignant hypertension is an extension over the papilla of retinal oedema.

As regards retinal classification our cases belong to Grades III and IV, Grade III showing angiospasm with nipping of veins at the arterio-venous crossings with or without haemorrhages or exudates, and Grade IV definite retinal oedema and papilloedema. Sedation tests were employed in the early cases, but when it was found that all received symptomatic relief in spite of unsatisfactory tests, these were abandoned.

Peet summarizes his criteria for operation as follows :

'A patient below 54 years of age, a more or less continuously elevated blood pressure with a systolic pressure over 170 and a diastolic pressure above 105. A non-protein nitrogen below $45 \mathrm{mg}$., a relatively well compensated heart and a relatively normal cerehral function.'

Now many cases fulfilling all these onditions may survive their expected span of life and it is very understandable that physicians are often hesitant in advising surgery for these patients. Patients with malignant hypertension, those with Grade III retinal changes and those with a history of definite encephalopathic attacks are, however, in a different category. In these people the prognosis is extremely gloomy and medical treatment can offer little help. It is strange to find that it is this very group of cases in which operation is deprecated by many authorities. Here the problem is akin to that of cancer. The cause is unknown, but the future, without treatment, can be predicted with reasonable certainty. In cancer any method of alleviation of symptoms or hope of lengthening life is rightly accepted by recognized medical opinion. The same should apply to hypertension. The strange fact that symptoms may be relieved, or cured, even when the blood pressure is not affected for more than a period of a few months, has now been noted by so many surgeons treating hypertension, that one feels that no patient should be denied the relief of an adequate sympathectomy, howevere severe the disease, unless he has reached the stage of advanced kidney damage where irreversible changes have occurred. It might be said that the indication for surgery, above all others, is hypertension with crippling headache and either Grade III or Grade IV retinal changes, before severe kidney damage has set in. There are, in our opinion, certain indications for urgent surgical treatment :-

(I) A rapidly progressive hypertension. The patient should be submitted to surgery before the inevitable cardiac and renal changes occur Adson $^{7}$ gives a limit of 18 months' survival to a rapidly progressive case.

(2) A fixed diastolic pressure above 130.

(3) A history of definite encephalopathic attacks, such as transient hemiparesis, marked mental changes and periods of unconsciousness.

(4) A young person with a rapidly mounting blood pressure.

In practice, in all cases at the Westminster Hospital, with one or two exceptions, operations have only been performed on severe hypertensives. From the surgeon's point of view as well as that of the patient, it is a great solace, after so extensive an operation that there is concrete evidence of improvement and that benefits are not only theoretical. The headache has gone and the eyesight improves. Seven out of our first eight cases are back at full work and asymptomatic. The eighth was a patient with advanced Grade IV retinal changes and severe renal damage who left hospital after his operation but soon returned and died of cardio-vascular-renal failure II weeks later.

It is extemely important that these patients should be treated by a team. They should be investigated, selected and assessed after operation by a physician. They are all subjected to the following routine pre-operative investigations :-

(I) X-ray and screening of chest.

(2) Intravenous pyelography.

(3) Electrocardiography. 




Vertebral Column.

Sympathetic Chain.

Greater Splanchnic

FIG. r.-Second stage Smithwick operation.
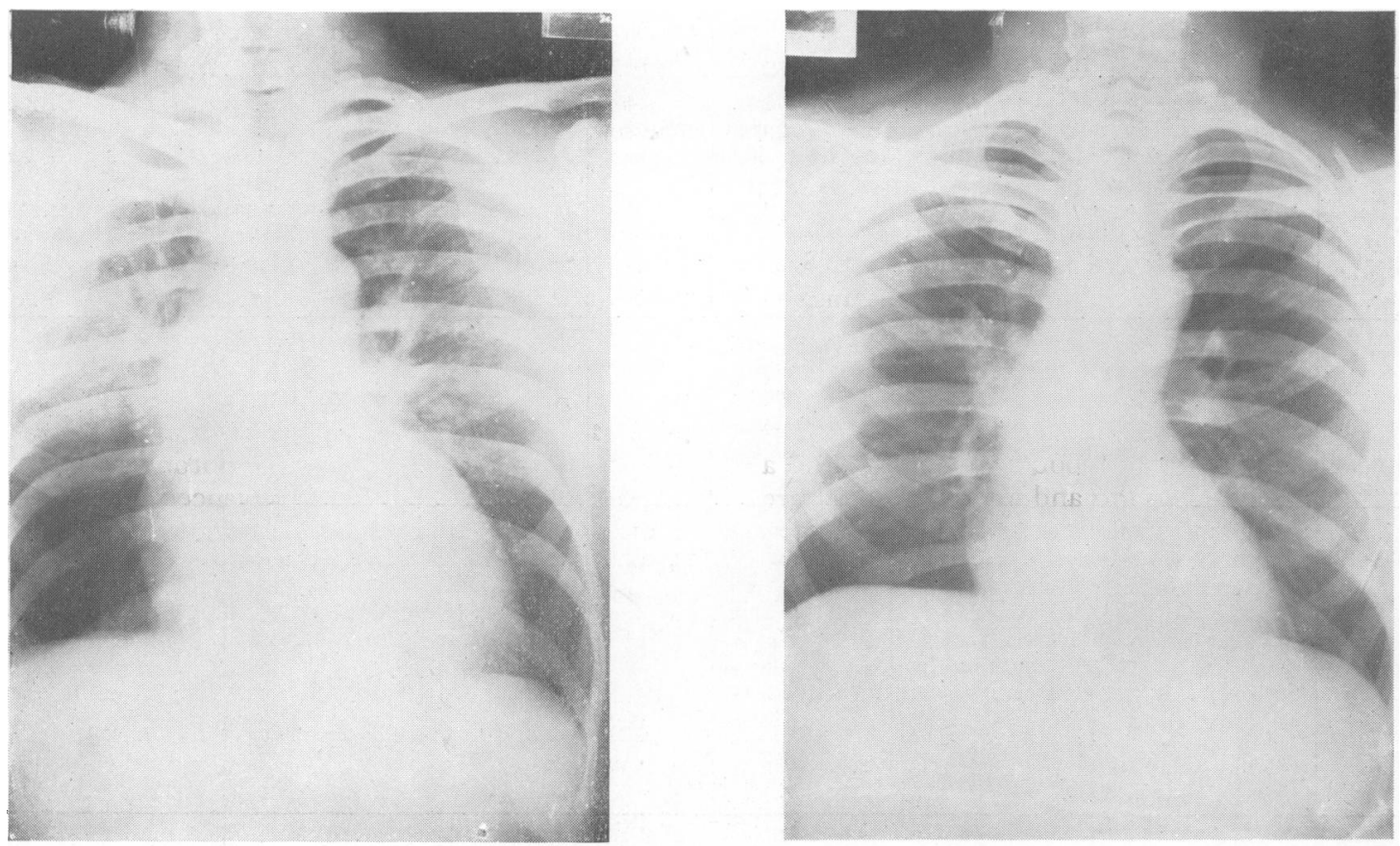
TABLE I

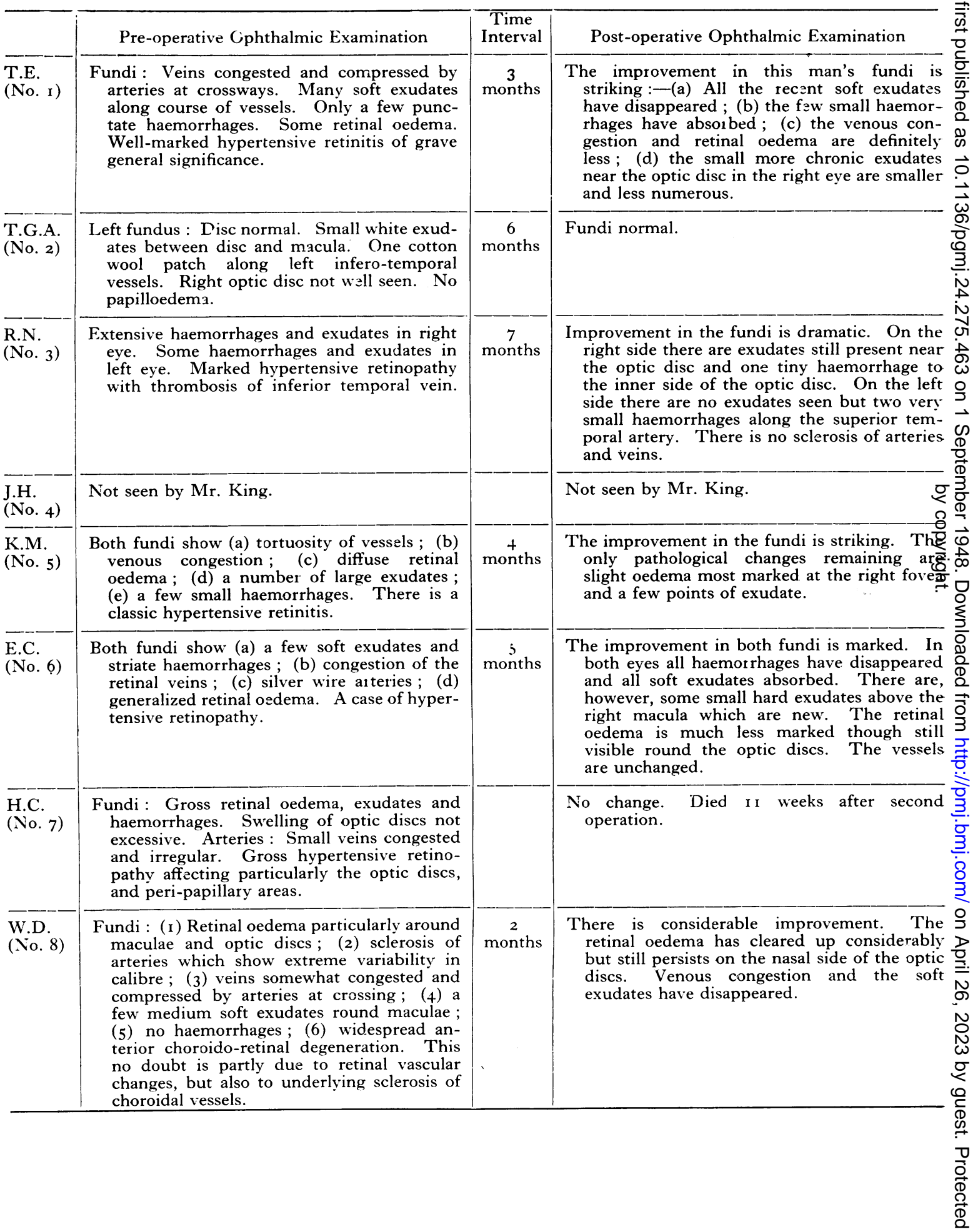


(4) Kidney function estimation.

(5) Examination of urine.

(6) Examination of fundi (and painting by artist).

(7) Serial blood pressure estimations.

(8) Sedation reaction.

Anaesthetization presents problems of its own. A most alarming fall in blood pressure has been noticed before any section or interference with sympathetic nerves has started and the pulse pressure often fades to a few millimetres of mercury. The cause of this is now under investigation. It may possibly be due to intense, generalized arterio-spasm, as improvement can be attained by the intravenous injection of Novocaine. That these cases show no operative mortality is largely due, I am sure, to careful anaesthesia.

\section{Operation}

The operative procedure in all these cases was that of Smithwick. The patient lies with his face downwards resting on the head-piece of the table. A dorsal para-vertebral incision is made $I \frac{1}{2}$ in. lateral to the vertebral spine, starting over the ninth rib. On reaching a point $I$ in. below the 12th rib, the incision curves laterally, below and parallel to the costal margin for a distance of 3-4 in. The sheath of the erector spinae is opened and the muscle mass reflected medially. The 12th rib is now resected sub-periosteally and the 12th nerve and sub-costal vessels excised. The renal fascia is next opened and the lower edge of the diaphragm is identified. The anaesthetist is asked to inflate the lung and the lower limits of the pleural reflection are thus seen. The diaphragm is cut parallel to this reflection and $\frac{1}{2}$ in. below it. Its division is continued until the side of the I2th vertebra is exposed. The kidney is displaced forwards after inspection of the suprarenal gland for any evidence of tumour. The table is then tilted laterally away from the operator to an angle of $45^{\circ}$. The sympathetic chain will thus be exposed lying over the heads of the ribs in the thorax and inclining forwards to the first lumbar ganglion. The greater splanchnic nerve is identified and traced down to the coeliac ganglion lying on the aorta and the lesser and least splanchnic nerves will be found lying parallel to it (Fig. I). Before removal of any part of these nerves they are traced upwards by reflecting the pleura, which is of tissue-paper thickness here, as far as possible from the vertebral ends of the ribs. One should be able to reach as high as the eighth ganglion. It may also be advantageous in some cases to remove the inner portion of the I Ith rib, to enable this level to be reached. All these nerves and the sympathetic chain itself are then removed from the highest point attained down to below the first lumbar ganglion. The coeliac ganglion is also removed completely. For some inches above the diaphragm, sympathetic filaments to the aorta should be removed, as should the pre-ganglionic nerves running from the spine to the sympathetic chain. It is recommended that the cut ends of the nerves be encased in silk sheaths turned on themselves and embedded in neighbouring muscle to discourage regeneration. The diaphragm is then re-sutured and the wound closed. The left side is done at the first stage and the right about two weeks later.

\section{Post-operative Complications}

I. Pleural effusion. An immediate post-operative $\mathrm{X}$-ray of the chest is taken as a routine and has shown in almost every case a pleural effusion. These, except in two cases, have been minimal, have not caused any symptoms and have cleared up in a few days. From two, a bloodstained sterile fluid was aspirated. No further treatment was required.

2. Lumbar neuralgia. Two cases complained bitterly of pain in the loin spreading down to the groin. These pains grew gradually less and in both cases disappeared when the patient got up from bed and became ambulatory, about a fortnight after the second operation.

3. Faintness and Giddiness. This occurs when a very marked fall of blood pressure is brought about by the sympathectomy and occurs when the patient first gets out of his bed. In our experience it is very uncommon in severe hypertensives but has only occurred in the patients not discussed in this paper, with less severe forms of essential hypertension. If these symptoms are marked, an abdominal pad and binder plus bandaging of the legs, will help.

Every case was examined by another important member of the team, the ophthalmic surgeon, who, in each case, provided us with a report on the fundi before and after operation. This was combined with actual painting of the fundi by a medical artist. A summary of the ophthalmic surgeon's reports (Mr. E. F. King) is shown in Table r. Table 2 gives some details of the eight cases treated. The pre-operative blood pressure was taken after full pre-operative investigation had been completed, while the patient was resting in bed. The post-operative blood pressure was taken at the interval stated when the patient reported for follow-up and was also taken in the recumbent position. It will be seen that there was no operative mortality and that all except one is now back at work and asymptomatic. No patient was considered too advanced for surgery, but it is certain that when irreversible changes take place in the kidneys - shown by a serious deficiency in kidney 
TABLE 2

\begin{tabular}{|c|c|c|c|c|c|c|}
\hline Age & Sex & $\begin{array}{l}\text { Duration of } \\
\text { Symptoms }\end{array}$ & $\begin{array}{l}\text { Pre-operative } \\
\text { Blood Pressure }\end{array}$ & Interval & $\begin{array}{l}\text { Post-operative } \\
\text { Blood Pressure }\end{array}$ & $\begin{array}{l}\text { Post-operative } \\
\text { Course }\end{array}$ \\
\hline $\begin{array}{l}\text { T.E. } 30 \\
\text { (No. I ) }\end{array}$ & $\mathbf{M}$ & 7 months & $205 / 135$ & 6 months & $180 / 135$ & $\begin{array}{l}\text { Symptomless no evi- } \\
\text { dence of cardiac } \\
\text { failure. Doing full } \\
\text { work. }\end{array}$ \\
\hline $\begin{array}{l}\text { T.G.A. } 40 \\
\text { (No. 2) }\end{array}$ & $\mathbf{M}$ & 3 months & $260 / 160$ & 5 months & $170 / 125$ & $\begin{array}{l}\text { Working hard-prob- } \\
\text { ably too hard. } \\
\text { Symptomless. }\end{array}$ \\
\hline $\begin{array}{l}\text { R.N. 42 } \\
\text { (No. 3) }\end{array}$ & $\mathbf{M}$ & 3 weeks & $260 / 150$ & 6 months & $\begin{array}{l}200 / 130 \\
.\end{array}$ & Symptomless. \\
\hline $\begin{array}{l}\text { J.H. } 48 \\
\text { (No. } 4 \text { ) }\end{array}$ & $\mathbf{M}$ & $\begin{array}{l}\text { Hypertension known for } \\
\text { 15 years. Symptoms } \\
\text { for one year. }\end{array}$ & $210 / 120$ & 5 months & $110 / 80$ & $\begin{array}{l}\text { Symptomless but tires } \\
\text { easily. }\end{array}$ \\
\hline $\begin{array}{l}\text { K.M. } 25 \\
\text { (No. 5) }\end{array}$ & F & $\begin{array}{l}\text { Headache for five years. } \\
\text { Blurring of vision for } \\
\text { two months. }\end{array}$ & $230 / 15 b$ & 4 months & $195 / 125$ & $\begin{array}{l}\text { Vision improved. Has } \\
\text { returned to work. }\end{array}$ \\
\hline $\begin{array}{l}\text { E.C. } 29 \\
\text { (No. 6) }\end{array}$ & $\mathbf{M}$ & 5 months & $210 / 145$ & 3 months & $200 / 135$ &  \\
\hline $\begin{array}{l}\text { H.C. } 47 \\
\text { (No. } 7 \text { ) }\end{array}$ & $\mathbf{M}$ & 6 weeks & $250 / 150$ & I month & $230 / 160$ & $\begin{array}{l}\text { Died II weeks after } \\
\text { operation. }\end{array}$ \\
\hline $\begin{array}{l}\text { W.D. } 34 \\
\text { (No. 8) }\end{array}$ & M & 2 years & $250 / 150$ & 6 weeks & $170 / 130$ & $\begin{array}{l}\text { Residual left visual } \\
\text { defect. Occasional } \\
\text { mild left sided head- } \\
\text { ache. }\end{array}$ \\
\hline
\end{tabular}

SYMPTOMATOLOGY

\begin{tabular}{|c|c|c|c|c|c|c|c|c|c|c|c|}
\hline & & & & T.E. & T.G.A. & R.N. & J.H. & K. .5. & E.C. & H.C. & $\stackrel{8}{\text { W.D. }}$ \\
\hline Headache & . & . & . & + & + & $\circ$ & + & + & + & + & + \\
\hline Impairment of visi & & . & . & $\circ$ & $\circ$ & + & $\circ$ & + & + & + & + \\
\hline Dyspnoea & . & . & .. & + & $\circ$ & $\circ$ & $\circ$ & $\circ$ & $\circ$ & $\circ$ & $\circ$ \\
\hline Encephalopathy & . & . & $\therefore$ & $\circ$ & $\circ$ & $\circ$ & + & $\circ$ & + & + & $\circ$ \\
\hline Fatigue & .. & . & . & $\circ$ & + & $\circ$ & $\circ$ & $\circ$ & $\circ$ & $\circ$ & $\circ$ \\
\hline Haemoptysis & $\ldots$ & $\ldots$ & $\ldots$ & + & 0 & 은 & 0 & 은 & 은 & 은 & 은 \\
\hline
\end{tabular}

function-little improvement can be expected. Case No. 7 was a malignant hypertensive with serious kidney damage, almost blind and suffering from crippling headaches. His blood pressure and eyesight were unaffected by operation but his headaches disappeared and he left hospital two weeks after his second operation. He returned after seven weeks and died of cardio-vascularrenal failure.

Table No. 3 shows the symptoms with which the 


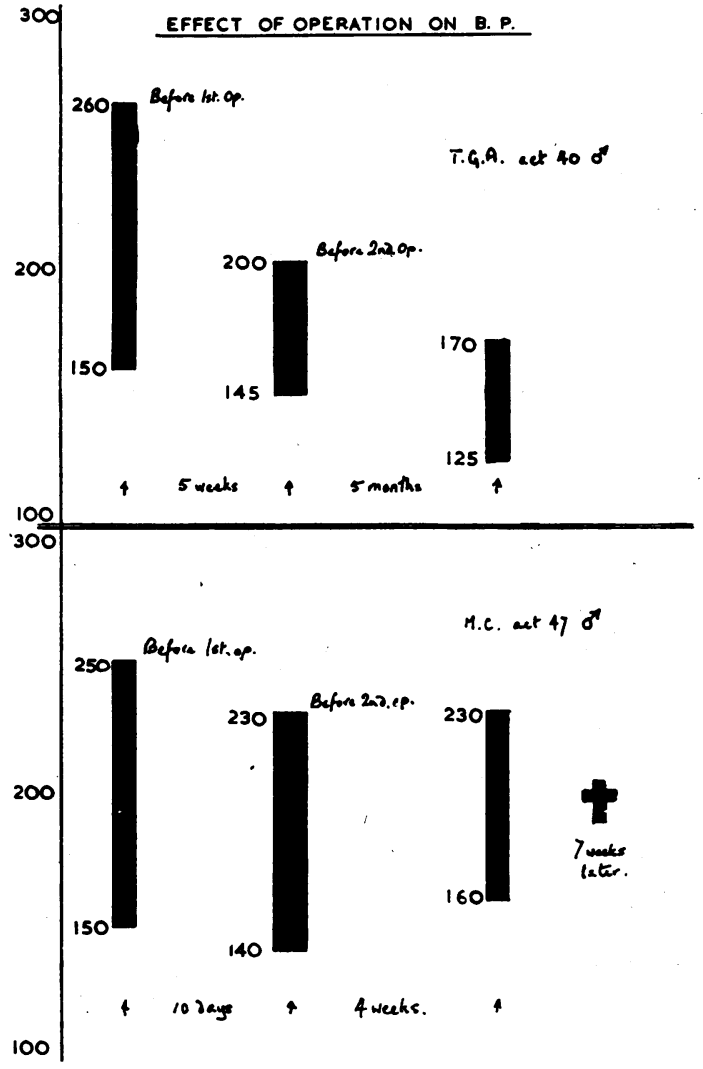

TABLE 4

patients presented themselves. It will be seen that headache was present in all except one case, impairment of vision in five and a history of definite encephalopathic incident in three.

No case over the age of 48 appears in this small series but recently a man aged 60 who had Grade II retinal changes only (definite arteriolar sclerosis) was sent us by a physician and has received great benefit from the operation.

Table 4 shows, in graphic form, the effects of operation on a man whose blood pressure reacted well to operation (Case No. 2), and below it is shown a chart of the blood pressure of the patient who received the least benefit and who eventually died (Case No. 7).

\section{Summary}

A series of cases ${ }^{-}$of severe types of essential hypertension is presented and the results analysed. It is found that they all received great benefit from the operation except one. That this improvement is not merely functional is shown by :-
(I) Its effects on the blood pressure.

(2) The improvement in the eyeground pictures and, in certain cases, diminution in the size of the heart (see Fig. 2).

It is urged that every case of marked hypertension should be given the chance of operation unless severe renal damage has set in or the patient has advanced arterial changes such as are present in old age. The operation is justified if symptoms are merely relieved. Its indications will be even more apparent if life is shown to be prolonged thereby.

My thanks are due to the physicians of the Westminster Hospital who investigated these cases and sent them to me for operation, particularly to to Sir Arnold Stott and Dr. S. P. Meadows. Also to Mr. E. F. King for his ophthalmic reports and to Dr. J. C. Harland and Mr. C. Drew, the medical and surgical registrars, respectively, for their help in preparing the data for this paper.

Since this article was submitted for publication a further I 7 cases have been submitted to operation. Of these 14 fulfilled the criteria laid down for severe cases ; 7 of these were definitely malignant cases with papilloedema. There has been one death and two have failed to derive any benefit, the first having a pre-operative renal function of 20 per cent., and the second advanced cardiac and pulmonary back pressure changes who has been recently re-admitted to hospital with heart failure. All the rest have benefited markedly as far as symptoms are concerned. All cases now have wound drainage for 48 hours after the operation and there has been a complete absence of the pleural effusion present in the early cases. The operative death occurred before drainage of the wound was instituted as a routine. At postmortem it was found that there was a large collection of blood hidden away deeply in the operative field. His low blood pressure post-operatively was put down to re-active hypotension and the condition not recognized. We feel that the loss of blood was a contributory factor to his death and where drainage is free and the haemoglobin concentration warrants it a blood transfusion is now given post-operatively.

\section{REFERENCES}

I. POPPEN, J. L., and LEMMON, C. (1947), f. Am. Med. Ass. I34, 4.

2. LEE MACGREGOR (1948), Brit. F. Surg., 139, p. 28 I.

3. GRIMSON, K. S. (194I), Ann. Surg., 114, 753.

4. PEET, M. M., and ISBERG, E. M. (1943), F. Am. Med. Ass., 130, 487.

5. SMITHWICK, R. H. (1945), Cleveland Clin. Quart., 12, 105.

6. DE TAKATS, G., HEYER, H. E., and KEETON, R. W. (1942), F. Am. Med. Ass., $118,506-7$.

7. ADSON, A. W. (1939), Milit. Surg., 84, 537. 